\title{
New Approaches in the Differentiation of Human Embryonic Stem Cells and Induced Pluripotent Stem Cells toward Hepatocytes
}

\author{
Iman Saramipoor Behbahan • Yuyou Duan • \\ Alexander Lam • Shiva Khoobyari - Xiaocui Ma • \\ Tijess P. Ahuja • Mark A. Zern
}

Published online: 19 February 2011

(C) The Author(s) 2011. This article is published with open access at Springerlink.com

\begin{abstract}
Orthotropic liver transplantation is the only established treatment for end-stage liver diseases. Utilization of hepatocyte transplantation and bio-artificial liver devices as alternative therapeutic approaches requires an unlimited source of hepatocytes. Stem cells, especially embryonic stem cells, possessing the ability to produce functional hepatocytes for clinical applications and drug development, may provide the answer to this problem. New discoveries in the mechanisms of liver development and the emergence of induced pluripotent stem cells in 2006 have provided novel insights into hepatocyte differentiation and the use of stem cells for therapeutic applications. This review is aimed towards providing scientists and physicians with the latest advancements in this rapidly progressing field.
\end{abstract}

Keywords Hepatocyte - Hepatocyte differentiation .

Hepatocyte transplantation - Human embryonic stem cells . Induced pluripotent stem cells

\section{Introduction}

Orthotropic liver transplantation is the only established treatment for end-stage liver disease. However, because of the shortage of viable livers available for transplant, many patients die while remaining on the extensive waiting list

I. S. Behbahan $\cdot$ Y. Duan $\cdot$ A. Lam $\cdot$ S. Khoobyari $\cdot$ X. Ma $\cdot$

T. P. Ahuja $\cdot$ M. A. Zern $(\bowtie)$

Transplant Research Program, Department of Internal Medicine,

University of California Davis Medical Center,

4635 2nd Ave. Suite 1001,

Sacramento, CA 95817, USA

e-mail: mazern@ucdavis.edu and many more are never added to the list. Utilization of hepatocyte transplantation and bio-artificial liver devices have been proposed as alternative therapeutic approaches to this problem [1, 2]. These two approaches, however, require an unlimited source of hepatocytes, and human primary hepatocytes provide the most desirable solution for cell therapies. Yet, the utilization of primary hepatocytes in therapy has been hindered by their slow growth, loss of function and de-differentiation in vitro [3]. Stem cells, possessing the ability to produce functional hepatocytes for clinical applications and drug development, may provide the answer to this problem. As yet, it is not clear which stem cell type will be the most effective in forming lines that will be effective in regenerative medicine. Hepatocytes-like cells have previously been derived from embryonic stem cells (ESC), bone marrow stem cells, adipose tissue, and mesenchymal cells, as well as multipotent progenitor cells in the human umbilical cord [4-10]. New discoveries in the mechanisms of liver development and the emergence of induced pluriplotent stem cells in 2006 have provided novel insights into hepatocyte differentiation and the use of stem cells for therapeutic applications. This review is aimed towards providing scientists and physicians with the latest advancements in this rapidly progressing field.

\section{Early Liver Development}

During embryogenesis, the differentiation of progenitor cells into fully mature hepatocytes depends on the initiation of complex pathways by numerous signals released from adjacent cells. Variations in timing and concentration of the cell signals are both necessary for the regulation of specific 
transcription factors that ultimately orchestrate this transition into mature cells. With the elucidation of the intricate mechanisms of liver development through recent discoveries in mouse, zebrafish and chicken embryos (reviewed by Si-Tayeb K et al. 2010 [11], Lemaigre FP 2009 [12]), new protocols of hepatocyte differentiation have begun to mimic the development of hepatocytes in vivo.

In a portion of the ventral endoderm located adjacent to the developing heart, the cells expressing albumin, transthyretin, and $\alpha$-fetoprotein (AFP) are the first molecular evidence for liver development $[13,14]$. At approximately 3 weeks of human gestational age, liver and pancreas progenitor cells in three separate regions of the endoderm, begin to differentiate: this is known as "specification". Then, two lateral progenitor regions move ventral-medially to form the hepatic endoderm [15] (Fig. 1a). At this stage, repression of mesodermal Wnt and Fibroblast Growth Factor (FGF) 4 are initially required for hepatic induction $[16,17]$. Retinoic acid signaling also helps determine the position of endodermal organs along the anterior-posterior position and also appears to help liver development from gut endoderm [18, 19]. Moreover, low concentrations of FGFs through activation of the mitogen-activated protein kinase (MAPK) pathway from cardiac mesoderm are necessary for liver programming. As a result, hepatic endoderm cells move away from the cardiac mesoderm cells to keep a lower concentration of FGFs [20, 21]. The interaction of FGFs with bone morphogenetic protein
(BMP)-2 and BMP-4 from the septum transversum appears to be essential to induce hepatic gene expression $[19,22]$. The ventral and lateral regions of the endoderm corresponding to specific hepatic and pancreatic regions have diverse responses to varying levels of FGFs and BMPs. Wandzioch and Zaret reported that during specification hepatic domains initially inhabit a region of high BMP activity at the ventral midline and high FGF activity at the lateral endoderm. Pancreatic progenitors initially develop in a region of low BMP activity; however, a region of high BMP activity is required to initiate the ventral pancreatic bud at the midline. The timing of BMP signaling for generating hepatic progenitor cells may be less important than it is for the pancreatic programming $[23,24]$.

The newly specified bipotent hepatic cells in embryos are known as hepatoblasts which express albumin and transthyretin, and are capable of becoming either hepatocyte or biliary epithelial cells [25] (Fig. 1b). After specification, the liver diverticulum forms from the primitive gut at day 22 of human embryonic age. Proliferation of these hepatoblasts then leads to the production of a pseudostratified epithelium-like tissue, called the hepatic bud $[12,26]$. Afterwards, the columnar hepatoblasts go through an epithelial-mesenchymal transition while invading into the septum transversum [11] (Fig. 1a). A complex transcriptional network consisting of factors such as GATA6 [27], prospero homeobox protein 1 (Prox1) [28], T-box

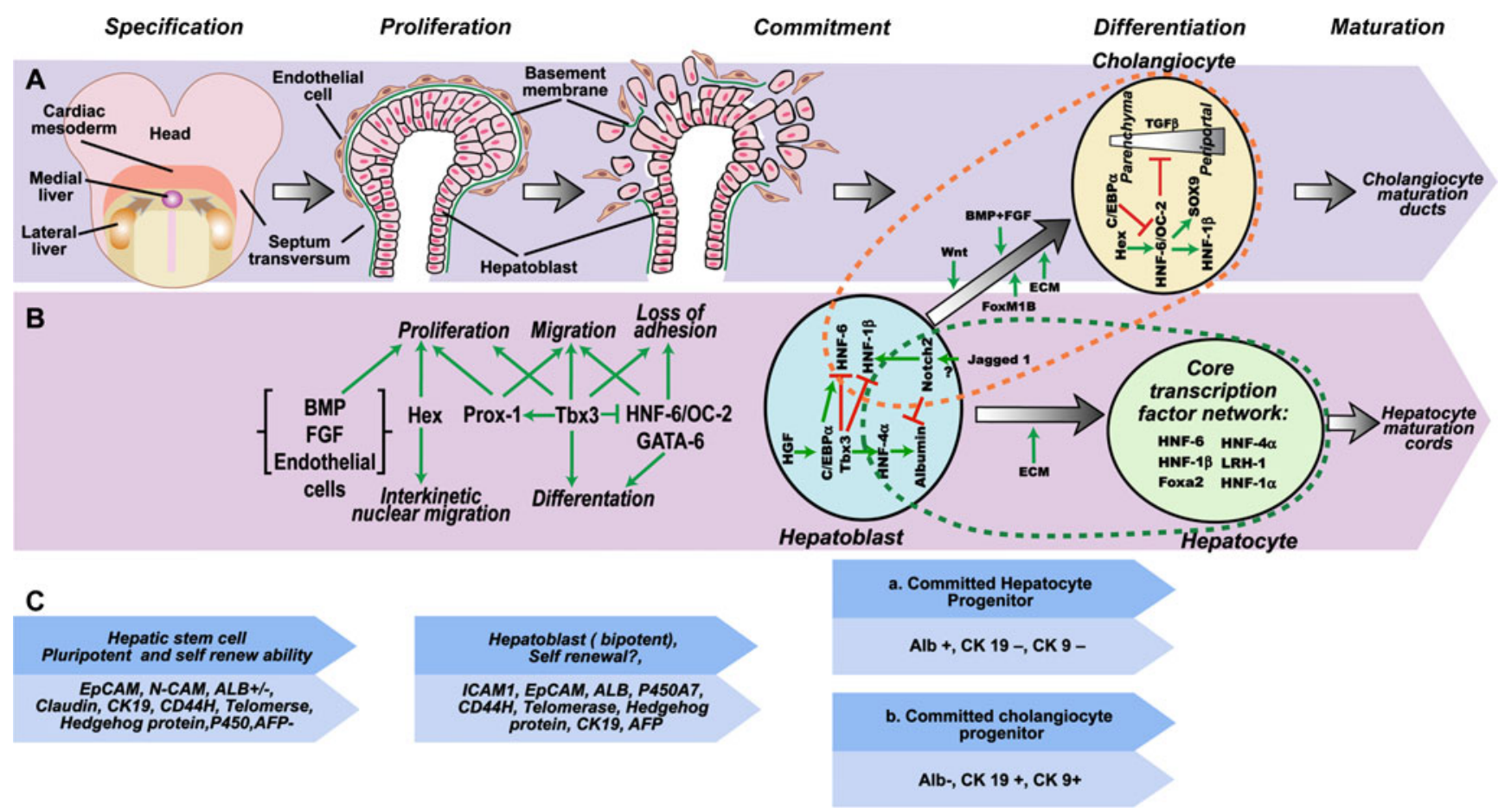

Fig. 1 Fetal liver development (adopted and modified from Ref. [12, 19, 32, 45]). a. Early liver development and liver bud formation; b. Transcription factors network involving in liver development; c. Some of the known markers suggested for each step 
transcription factor 3 (Tbx3) [29], hepatocyte nuclear factor 6 (HNF-6) [30] and HNF-4 [31] control these events [12]. (Fig. 1b).

\section{Fetal Hepatic Lineage Commitment and Hepatocyte Maturation}

The development of the embryonic liver results in three distinct cell populations, which differ in their cell markers and induction signals. Hepatocyte-committed cells are recognized by extensive expression of albumin and AFP. Cholangiocyte-committed cells are distinguished by their cytokeratin (CK)-19 expression. The cell population expressing both hepatic and biliary markers is the bipotent hepatoblast $[11,12,32]$. Oncostatin M (OCM) which is expressed in hematopoietic cells in the fetal liver [33] along with glucocorticoids $[32,34]$ suppress the differentiation toward the hematopoietic lineage and promote the differentiation of the liver progenitor cells towards hepatocytes in vitro [11, 32, 35]. Meanwhile, some mitogenic factors from sinusoidal endothelial cells such as hepatocyte growth factor (HGF) and interleukin 16 (IL-16) acting via the vascular endothelial growth factor (VEGF) receptors enhance hepatocyte proliferation [11]. HGF inhibits the progression of the cells into the cholangiocytic lineage by the blocking of notch signaling. This enhancement of hepatocyte specification appears to be stimulated by insulin. Gradually, during fetal hepatic maturation the number of bipotent hepatoblasts decreases and the number of mature cells expressing specific hepatic or biliary markers increases [11]. During this process, AFP is highly expressed in early embryonic and fetal liver development, then the production of AFP decreases later in maturation and is markedly lower in adulthood $[32,36]$. Finally, whole liver maturation occurs after birth by a combination of growth factors secreted by surrounding non-parenchymal liver cells, such as HGF, FGF4, and epidermal growth factor (EGF) [11].

\section{Liver Stem Cells}

In the injured liver, a heterogeneous population of progenitor cells in or adjacent to the canal of Hering become activated [37]. Farber first described them as "small oval cells with scant lightly basophilic cytoplasm and pale blue-staining nuclei" with a high nuclear/cytoplasmic ratio [38]. "Oval cells" are recognized as bipotent hepatoblasts possessing the ability to differentiate into either hepatocytes or biliary epithelial cells and express both hepatocyte (AFP, albumin) and cholangiocyte (CK 7, CK 19, OV-6) markers [39]. In addition, activation of stem cell genes such as c-kit
[40], CD34 [41], flt 3 receptor [42] and leukemia inhibitory factor (LIF) [43] has been reported during oval cell propagation. It is suggested that oval cells produce ductlike structures in the periportal regions and expand into the liver acinus; after several days, clusters of small basophilic hepatocytes and mature bile ducts form from these duct-like structures [44].

Previously, bipotent hepatoblasts were recognized as the only human hepatic stem cell. Recently, adult hepatic stem cells were characterized by their multipotency and self-renewal capacity. Hepatic stem cells and hepatoblasts are now considered the multipotent progenitor populations in human liver. The ductal plates of fetal and neonatal livers and the canals of Hering in pediatric and adult livers are proposed to be their niche $[45,46]$. Both cell populations express albumin, CK8, CK18, and CK19, Sonic and Indian Hedgehog proteins, telomerase, and $\mathrm{CD} 133$, and they are negative for hematopoietic markers (CD45, CD38, CD14, and glycophorin A), hepatic stellate cell markers (desmin, $\alpha$-smooth muscle actin, and CD146), and endothelial cell markers (VEGFr, CD31, and van Willebrand's factor) [45-47]. The hepatic stem cell population which is thought to be the precursors of hepatoblasts express epithelial cell adhesion molecule (EpCAM), neural cell adhesion molecule (NCAM), CK19, as well as \pm albumin, and are also negative for AFP. Hepatoblasts are characterized by the expression of the combination of EpCAM, intercellular cell adhesion molecule (ICAM-1), CK19, albumin++, and AFP++ [45, 47] (Fig. 1c).

\section{Human Embryonic Stem Cells Differentiate Toward Hepatocytes}

ESC are continuously growing stem cell lines of embryonic origin first isolated from the inner cell mass of blastocysts from the developing mouse embryo[48]. Later, hESCs were successfully derived from in vitro fertilized human embryos [49]. It has been shown that hESCs possess a normal karyotype [50] with high levels of telomerase activity [51] and express specific markers. They also show continuous renewal capability [52]. Hundreds of hESC lines have been created with more than a hundred in the National Institutes of Health registry (http://stemcells.nih.gov/research/registry/) [53]. These cells have been shown to differentiate into nearly all human cell types [51, 54]. Abe et al. in 1996, as well as Levinson-Dushnik and Benvenistry in 1997, demonstrated the ability of mouse ESC (mESC) to differentiate into endodermal cells $[55,56]$. Duncan et al. not only showed that mESC cells were capable of differentiating into visceral endoderm cells, but also established the capacity of the cells to produce liver-specific proteins [57]. Later, Hamsaki et al. 
reported the use of specific growth factors to drive mESC into hepatocyte-like cells [58]. The differentiation of hESC into hepatocytes was first demonstrated by Rambhatla et al. in 2003[59]. Since then, many studies have focused on enhancing the culture conditions to obtain a more homogeneous cell population

Differentiation via Embryoid Bodies (EB)

without Activin A

Human ESCs undergo spontaneous differentiation into the three germ layers, among them endodermal cells expressing AFP and albumin [60, 61]. Lavon et al. demonstrated that hESC differentiated into hepatic-like cells through the intermediates step of EB formation. They showed that albumin-expressing cells isolated by fluorescence activated cell sorting were capable of growing in vitro for a few weeks $[62,63]$.

Our group, among others, extended the original finding by optimizing growth factors, ECM, and medium selection to enhance the purity of the differentiation process using EBs [64-68]. In addition, it was suggested by Baharvand et al. that plating EB in a 3D collagen type I scaffold with the sequential addition of growth factors is more efficient than applying 2D cultures. They also reported the migration of cells out of aggregates and the formation of multilayer cord-like structures in a 3D culture system [66]. However, hepatocyte differentiation through EBs is no longer considered the most effective approach. The major problem is the relatively low differentiation rate and non-homogeneous population of cells after differentiation.

\section{Stepwise Differentiation}

\section{Differentiation toward Definitive Endoderm Employing Activin a}

During gastrulation, epiblast migration inward from the primitive streak forms the definitive endoderm germ layer. Later, the primitive buds of the liver, lung, thyroid and ventral rudiment of the pancreas will develop from the anterior-ventral domain of the foregut endoderm. Nodal signaling, a member of the transforming growth factor- $\beta$ (TGF- $\beta$ ) superfamily, plays a critical role in the activation of transcription factors which initiate the development of endoderm. Activin A, an agonist for two types of cell surface transmembrane receptors, initiates this nodal pathway by binding to the type II receptor. This then elicits a cascade response via the recruitment and phosphorylation of various type I Activin receptors, eventually resulting in the phosphorylation of SMAD2 and SMAD3. SMAD2 and SMAD3 then translocate to the nucleus, complex with SMAD4, and initiate the activation of gene-specific transcription factors [69-71]. Hepatocytes differentiate from the endoderm during embryonic development [72]. The seminal study was accomplished by D'Amour and colleagues who reported differentiation of hESC to definitive endoderm with more than $80 \%$ purity using Activin A and low serum [73]. The most effective hepatocyte differentiation protocols have employed this approach of definitive endoderm formation as the first step.

Ishii et al. compared endodermal differentiation through EB or without forming EBs on different ECMs. They found the best result by employing Matrigel-coated dishes with100 ng/ml Activin A without employing EBs. In addition, they showed that HGF, BMP4, and FGF4 have no significant effect on endodermal differentiation, and, they suggested an inhibitory effect of all-trans-retinoic acid on endodermal differentiation. The presence of BMP4 and/ or FGF4 reduced the effects of Activin A and HGF on endodermal differentiation [74].

Brolén et al. showed that using Activin A and FGF2 together enhanced the expression of endodermal markers ( Sox17, HNF3 $\beta$ and CXCR4 ) in comparison with using Activin A alone [75].

Hay and colleagues examined Wnt3a expression in liver at different times during human liver development. They reported that in the first trimester Wnt3a activity developed in the portal system with no parenchymal expression. In contrast, in the second trimester Wnt3a expression was observed both in the portal region and in the liver parenchyma suggesting a potential role in early hepatogenesis. Furthermore they found enhanced endodermal differentiation of hESC using ActivinA plus Wnt3a in comparison with Activin A plus sodium butyrate. They postulated that Activin A plus Wnt3a induced a rapid and more homogeneous hepatic endoderm production and led to more functional hepatocyte-like cells [76].

\section{Hepatic Induction}

As mentioned above, FGFs and BMPs appear to play significant roles in liver specification. Jun Cai et al. reported that FGF4 or BMP2 alone in the culture medium had little effect on liver specification from definitive endoderm of hESC. However, their combination lead to a significant increase in albumin expression in vitro, and this effect was confirmed by the FGFR1 inhibitor Su5402 or the BMP inhibitor Noggin. Also, they showed definitive endoderm induction is essential for the effectiveness of FGF4 and BMP2 on hepatic induction. They reported similar results for the combinations of aFGF and BMP4, bFGF and BMP4, or FGF4 and BMP4 [77]. DMSO, which modifies histone acetylation, appears to have an inductive effect toward hepatocyte lineage specification and has been utilized in some protocols $[4,76,78]$. 
Brolén et al. used the combination of BMP $2 / 4$ and FGF1/2/4 for hepatic induction. They observed multiple EpCAM-expressing cell clusters with adjacent groups of CK7, CK19 positive cells and some CD54 positive areas. In the control group which was not induced by BMPs and FGFs, although EpCAM, $\alpha 1$-antitrypsin, AFP, CK7/8/18/ 19 and CD54 positive cells appeared, there was a considerable cell morphology difference with a significant decrease in liver-specific gene expression [75].

Johannesson et al. found that Activin A-treated hESC tend towards the hepatic lineage instead of towards pancreatic progenitor cells if they are not treated with FGF4 and retinoic acid (RA) [79]. On the other hand, Ameri et al. reported a dose-related response to FGF2 regarding cell fate selection. They demonstrated low levels of FGF2 enhanced hepatic induction while intermediate doses of FGF2 resulted in pancreatic fate selection [80]. In summary, many factors have been shown to affect hepatic induction including the timing, concentration and specific variety of growth factors, as well as the methods of generating definitive endoderm.

\section{Maturation}

In this step, differentiated cells present a polygonal hepatocyte morphology with distinct round nuclei that have cytoplasmic vacuoles [76, 81]. Hepatocyte maturation strategies are designed to replicate the role of growth factors in liver development (see above). In general, sequential and different levels of HGF and/ or, OSM or EGF with glucocorticoids and insulin in a hepatocyteoptimized culture medium are used (See Table 1).

\section{Differentiation toward Liver Precursor Cells}

The isolation of a hepatic precursor cell line derived from $\mathrm{hESC}$ has drawn the attention of some researchers because the establishment of a method to drive hESC or iPS cells to a stable bipotent liver stem cell line which has renewal capability would bypass many expensive and difficult differentiation steps and would enhance clinical applications that require a large quantity of cells. Haiyun Pei and colleagues reported the isolation of liver progenitor-like cells which were isolated from portal zone 1 that expressed stromal progenitor markers, such as CD29, CD44, CD71, CD90, and CD105, and were negative for CD34 and CD45 [82]. Zhao et al. studied N-cadherin-expressing hepatic endoderm that was derived from hESC by induction of definitive endoderm and then treatment with BMP2 and FGF4 for 5 days. These cells were maintained and passaged on mouse embryonic stromal feeders cells for more than 100 days. They also reported that these cells can be differentiated toward hepatocyte- and cholangiocyte-like cells [83].

\section{Differentiation of iPSCs Toward Hepatocytes}

Induced pluripotent stem cells (iPSCs) are defined as reprogrammed somatic cells that have properties of pluripotent stem cells. Since the first report of the generation of iPSCs by Yamanaka and colleagues from mouse fibroblasts in 2006 [84], many studies have reported iPSC formation from species including mouse, rat, monkey and human [85]. Typically, iPSCs are generated by retroviral induction of transcription factors, Oct3/4, Sox 2, KLF4 and c-Myc, in fibroblasts [85]. Lentivirus and adenovirus induction, induction with other gene combinations and virus free approaches such as using plasmids, small molecules and recombinant proteins have also been reported $[85,86]$. In addition, it has been shown that iPSCs can be generated from a variety of cell types such as pancreatic cells, meningiocytes, keratinocytes, hematopoietic cells differentiated from ESCs, and primary human hepatocytes [85, 87, 88]. iPSC lines generated from patients suffering specific diseases provide a unique source for study and disease modeling. For example, iPSCs generation has been reported from individuals with juvenile diabetes mellitus, Down syndrome, muscular dystrophy, neurodegenerative diseases, as well as ischemic heart failure, Parkinson's disease, Alzheimer's disease, diabetes mellitus, sickle cell anemia and Huntington's disease, and the list is growing daily [87, 89]. In addition, iPSCs provide a potentially unlimited source for autologous cell therapy for regenerative medicine. It has been shown that human iPSCs can be differentiated to many tissues such as hematopoietic precursors and functional osteoclasts [90], pancreatic insulin-producing cells [91], cardiomyocytes [92], photoreceptors [93], as well as neural conversion [94]. Recently, mice have been cloned from iPSCs, which is another proof of the pluripotency of these cells $[95,96]$.

iPSCs is a favorable choice for hepatocyte generation because of their pluripotency and potential source for autologous hepatocyte transplantation. Differentiation of iPSCs toward a hepatic lineage has been shown in mice $[97,98]$ and in humans [99-101] using similar protocols as for hESC cells (Table 2). Si-Tayeb et al. demonstrated that iPSC-derived mouse embryos similar to control fetal livers consist of hepatocytes, endothelial cells, and sinusoidal cells that express specific genes and markers at the same level as in the control livers. In addition, they showed that human iPSCs generated from foreskin fibroblasts by lentiviral transduction of OCT3/4, SOX2, NANOG and LN28 are capable of differentiating toward functional hepatocytes by a four-step differentiation protocol and low 


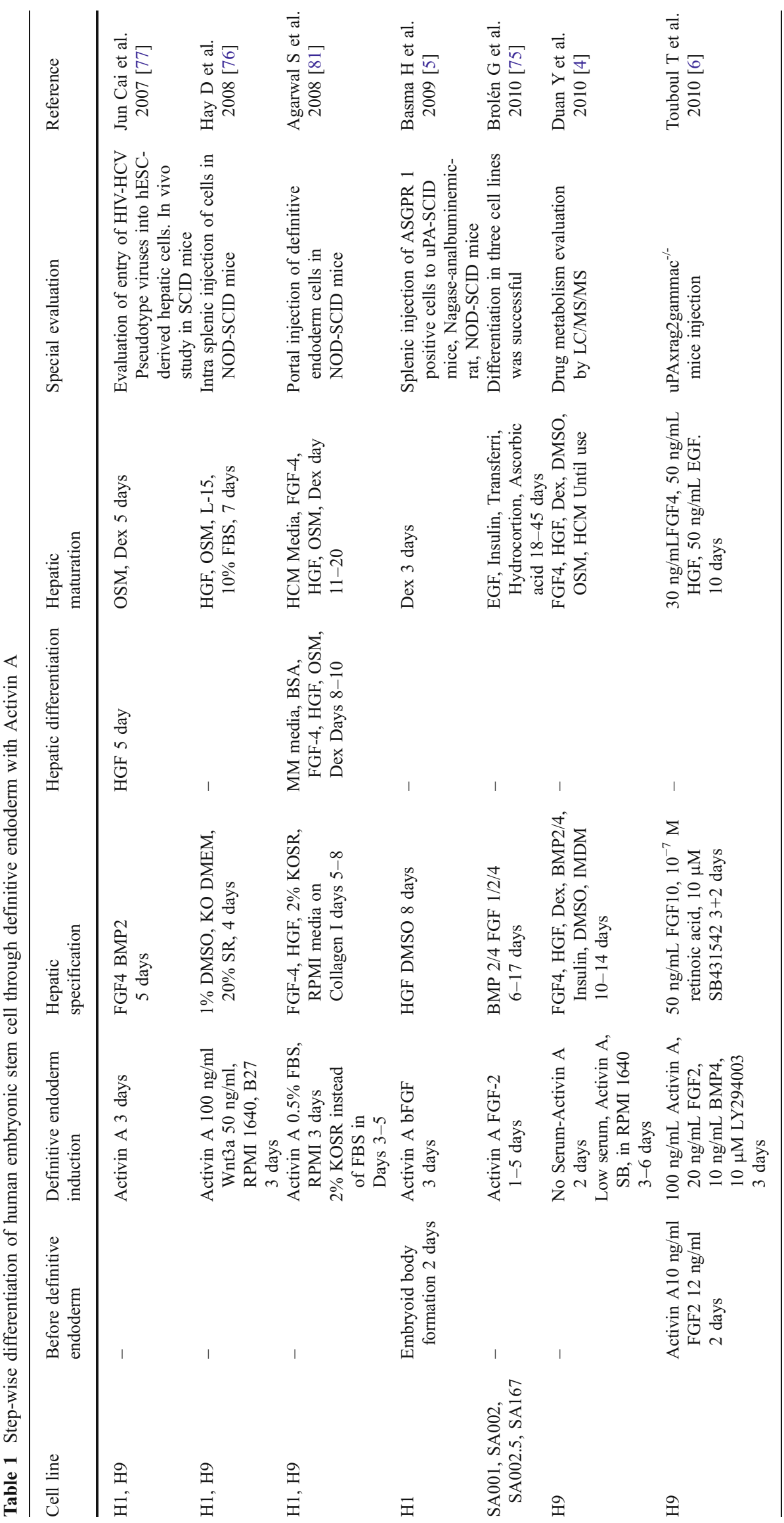




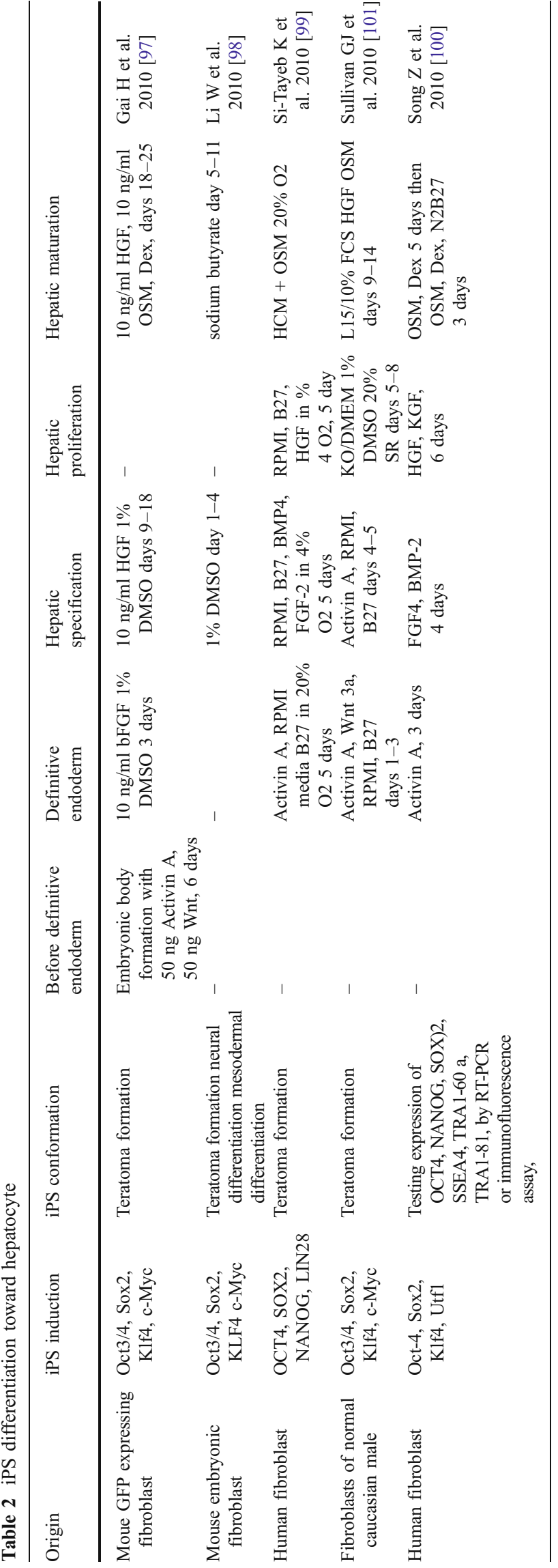

oxygen content. They demonstrated that these cells proliferated in mouse fetal liver for 7 days after cell transplantation in vivo as well [99]. Song $\mathrm{Z}$ et al. reported the differentiation of human iPSC toward functional hepatocytes with a multi-phasic protocol, with $60 \%$ producing AFP and albumin, similar to hESC differentiated to hepatocytes [100]. Sullivan et al. generated three human iPSC lines by retroviral induction of Oct4 Sox2, Klf4, and c-MYC. They showed that all three cell lines can differentiate to hepatic endoderm which they characterized with albumin and E-cadherin production, AFP, hepatocyte nuclear factor-4a and cytochrome P450 7A1 expression [101].

\section{Oxygen Pressure and Mitochondrial Function in Hepatocyte Differentiation}

Early embryonic development mostly occurs in low oxygen concentration. In addition, hypoxic microenvironments in adults provide adult stem cell niches that control cellular differentiation [102, 103]. The effect of low oxygen on embryonic stem cell culture is controversial [104]. Low oxygen seems to decrease the chance of spontaneous differentiation in $\mathrm{mESC}$ culture conditions in some reports; however other studies suggest that it reduces the expression of pluripotency genes. Low oxygen concentration enhances the production of some lineages such as neurons, cardiomyocytes, hematopoietic progenitors, endothelial cells, and chondrocytes (reviewed in references [102] and [104]). Multiple $\mathrm{O}_{2}$-sensitive intracellular mechanisms such as hypoxia-inducible transcription factors (HIFs), the environmental sensing of mammalian target of rapamycin (mTOR) and the endoplasmic reticulum (ER) stress response have been described [102]. It appears that hypoxia increases the mitochondrial membrane potential and subsequently reactive oxygen species which activate HIF-1 expression [105].

Si-Tayeb et al. used different oxygen pressures during the differentiation of hESC and hiPSC to hepatocytes. They maintained undifferentiated hESC and hiPSC at low oxygen pressure then generated the definitive endoderm at a normal oxygen pressure, and finally hepatic induction and specification was performed in a hypoxic environment. A high percentage of hepatic differentiation is reported. However, the advantage of the different oxygen pressures is not discussed in comparison to a control group [99].

\section{Characterization and Functional Evaluation of Differentiated Hepatocytes and Drug Metabolism}

There is no consensus for the characterization of hepatocyte-like cells derived from stem cells. Generally, 
hepatocyte-like cells are recognized by their morphology, liver-specific mRNAs, protein markers and their functional abilities in each phase of differentiation [32]. Each phase of differentiation is delineated by specific markers. SOX17, GSC and FOXA2 are well-known markers of definitive endoderm $[32,73]$. Primary hepatic differentiation is often assessed by the expression of HNF3b, AFP, and transthyretin (TTR). The intermediate phase of hepatogenesis is recognized by HNF $1 \alpha, \mathrm{HNF} 4 \alpha$, Albumin, and CK18. Finally, mature hepatocytes are defined by such markers as tryptophan-oxygenase (TO), tyrosine amino-transferase (TAT), C/EBP $\alpha$, specific CYPs and asialoglycoprotein receptor 1(AGPR1) [32]. Several metabolic tests are used for functional assays of differentiated hepatocytes. Glycogen accumulation is examined by periodic acid shift staining as one of the mature hepatocyte characteristics [4, $59,67,76]$. Under electron microscopy the appearance of polygonal-shaped cells containing multiple nuclei is suggestive of hepatocytes. With transmission electron microscopy, glycogen granules within the cells, round nuclei with evenly distributed chromatin and Golgi complexes, welldeveloped bile canaliculi with apical microvilli and tight junctions are considered to be characteristics of mature hepatocytes in some studies [5, 67]. Hepatocyte-specific functions such as urea synthesis and albumin production are common functional evaluations in hepatocyte differentiation $[4,32,68]$. Uptake of low-density lipoprotein (LDL) has been utilized as well [67, 77]. Indocyanine Green is a synthetic dye that is taken up by hepatocytes and secreted into bile ducts without conjugation [106]. Its uptake and secretion is specific to hepatocytes and thus are used to determine hepatocyte-specific function $[4,59,67,68]$. Other hepatocyte-specific functions have been evaluated infrequently, such as measurement of coagulation factor VII activity [5] and entry of HIV-HCV pseudotype viruses into hESC-derived hepatic cells [77].

Drug discovery is one of the important applications of hepatocyte-like cells, and some studies have evaluated the drug metabolism ability of hepatocyte like-cells derived from hESC [107]. For example, the pentoxyresorufin-O-dealkylase (PROD) assay for the assessment of the cytochrome p450 system has been demonstrated in some studies[77], and Ek M et al. demonstrated UDP-glucuronosyltransferases (UGTs), drug transporters, transcription factors and other liver-specific genes including several important CYPs at the mRNA and protein levels in their hESC-differentiated hepatocytes [107]. In addition, CYP3A4 induction of hESC-derived hepatocytes by rifampin and midazolam is described using LC-MS/MS in comparison with Hep G2 by Agarwal and colleagues [81]. The conversion of testosterone to 6-beta-hydroxytestosterone, a specific measure of CYP 3A4-mediated metabolism, and inducible hepatic CYP 1A1/1A2-mediated EthoxyresorufinO-deethylase (EROD) activities have been reported as well
[5]. We first systematically evaluated the presence and distribution of the biotransforming enzymes/proteins and their regulators, the nuclear receptors, and determined the real-time activities and functions of these biotransforming enzymes/proteins in hESC-derived hepatocytes [4]. Using ultra performance liquid chromatography-tandem mass spectrometry technology our group identified seven metabolic pathways of the drug bufuralol including four newly-reported ones in hESC-derived hepatocytes, which were the same as those in freshly isolated human primary hepatocytes. In addition, the results of the metabolism of four drugs indicate that our hESC-derived hepatocytes have the capacity to metabolize these drugs at levels that are comparable to primary human hepatocytes [4].

\section{In Vivo Studies}

Although transplantation is one of the potential goals of hepatocyte generation from hESC, only a few studies have evaluated these cells in vivo. Jun Cai et al. showed that differentiated hESCs were able to engraft in the livers of SCID mice injured by $\mathrm{CCl}_{4}$ and they expressed human alpha-1 antitrypsin for at least 2 months [77]. Our group transduced hESC-differentiated hepatocytes using a lentiviral vector containing triple fusion protein and transplanted transduced hESC-differentiated hepatocytes into the livers of NOD-SCID mice [68]. Then we investigated the luciferase-induced bioluminescence in the animal livers by a charge-coupled device camera. We showed that the transplanted cells had engrafted into the liver and were functional [68]. Agarwal et al. transplanted definitive endoderm cells derived from hESCs into the portal vein of NOD-SCID mice that previously were treated with $\mathrm{CCl}_{4}$ and retrosine, and they detected that the cells expressed human-specific mitochondrial antigen, as well as CD26 and alpha-1-antitrypsin in the livers of the injected mice over time [81]. Hay et al. showed that hepatocyte-like cells could engraft in the NOD-SCID mouse liver. They reported that Wnt3a-treated cells expressed higher levels of human albumin in the serum than did the control cells [78]. Basma et al. isolated the ASGPR positive cells from differentiated hepatocyte-like cells by flow cytometery. Then, they transplanted these cells into the spleen of Alb-uPA SCID mice. Very high levels of human albumin $(1,000-2,000 \mathrm{ng} / \mathrm{ml})$ and alpha-1-antitrypsin were detected in the animals' serum 75 days after transplantation. In histological evaluation, small clusters of human CD18-expressing cells without any tumor formation were observed. Then intrasplenic injection of one million sorted cells was performed in an FK506immune suppressed Nagase analbuminemic rat or NODSCID mice after $70 \%$ or $50 \%$ partial hepatectomy and retrosine treatment. They reported 20,000 ng/ml human 
albumin in the transplanted animal's serum with large clusters of human engrafted cells in histological evaluation. However, a well-differentiated adenocarcinoma was detected as well [5]. hiPSC-generated hepatocytes were injected into the right lateral liver lobe of neonatal mice by Si-Tayeb et al. After 7 days, human albumin-expressing, integrated hepatocyte-like clusters of cells were observed in the injected lobe [99].

\section{Future Challenges}

The differentiation of hESC and other stem cells along a hepatocyte lineage has undergone enormous changes over the last decade. The progress has been substantial, with the greatest paradigm shift being the emergence of hiPSC which resolve many of the ethical issues surrounding hESC. Although the progress towards the development of improved protocols is impressive, a number of problems exist before the cells can be used for cell transplantation trials in humans or for toxicology or pharmacology studies. For example, xeno-free and feeder free growth and differentiation conditions must be established which are effective, reproducible, robust, and relatively inexpensive. This may include the development and use of small molecules and synthetic biocompatible ECMs which can substitute for the highly expensive growth factors and xeno-derived ECMs.

New approaches may be developed in the near future that may be even more effective than our present technology of differentiating hepatocytes. For example, recent reports have shown the transdifferentiation of fibroblasts to neuronal cells and cardiomyocytes [108-111]. Thus one of the future approaches may be the similar direct differentiation of fibroblasts to hepatocytes or hepatic progenitor cells.

Despite continual improvements in in vitro function, the engraftment and proliferation of hepatocyte-like cells from hESC and hiPS has in general been disappointing in rodents. One likely explanation is that the differentiated human cells may not be compatible with the extracellular matrix and growth factor niche of rodent livers. Thus it may be that nonhuman primates will provide a better environment for hepatocyte engraftment, differentiation, and proliferation. Moreover, studies conducted in nonhuman primates will obviously be better indicators of results in humans.

Tumorogenisity is still one of the main obstacles in the clinical application of hiPSC and hESC, and a major question is how safe must the cells be before they can be used? How does one define lack of tumorogenisity? What is an acceptable risk, and how does one determine that a differentiated cell population is free from the presence of any early progenitor cells? Another major issue is the loss of proliferation of cells when they become significantly differentiated. This leads to the question of whether a sufficient number of mature hepatocyte-like cells that have been derived from hESC or hiPSC can be obtained so that cell transplantation can be clinically effective. Another variant of this question is at what stage should cells that are undergoing differentiation be transplanted? Should they be transplanted at an early progenitor stage when they are rapidly proliferating, yet not mature, or wait until they are fully differentiated yet much less proliferative?

These are but a few of the many technical questions that must be addressed in the coming years by investigators in the field as our new-found success makes technical questions take the forefront of research endeavors, and basic research yields to translational approaches.

Acknowledgement This work was supported by NIH grant DK075415 (to M.A.Z.), California Institute of Regenerative Medicine RC1-00359 (to M.A.Z.), Alpha-1 Foundation (to M.A.Z.), and a pilot grant from the UC Davis Genome Center (to Y.D.).

Disclosures The authors indicate no potential conflicts of interest.

Open Access This article is distributed under the terms of the Creative Commons Attribution Noncommercial License which permits any noncommercial use, distribution, and reproduction in any medium, provided the original author(s) and source are credited.

\section{References}

1. Ito, M., Nagata, H., Miyakawa, S., \& Fox, I. J. (2009). Review of hepatocyte transplantation. Journal of Hepatobiliary Pancreatic Surgery, 16(2), 97-100.

2. Carpentier, B., Gautier, A., \& Legallais, C. (2009). Artificial and bioartificial liver devices: present and future. Gut, 58(12), 16901702.

3. Clayton, D. F., \& Darnell, J. E., Jr. (1983). Changes in liverspecific compared to common gene transcription during primary culture of mouse hepatocytes. Molecular and Cellular Biology, 3 (9), 1552-1561.

4. Duan, Y., Ma, X., Zou, W., Wang, C., Bahbahan, I. S., Ahuja, T. P., et al. (2010). Differentiation and characterization of metabolically functioning hepatocytes from human embryonic stem cells. Stem Cells, 28(4), 674-686.

5. Basma, H., Soto-Gutierrez, A., Yannam, G. R., Liu, L., Ito, R., Yamamoto, T., et al. (2009). Differentiation and transplantation of human embryonic stem cell-derived hepatocytes. Gastroenterology, 136(3), 990-999.

6. Touboul, T., Hannan, N. R., Corbineau, S., Martinez, A., Martinet, C., Branchereau, S., et al. (2010). Generation of functional hepatocytes from human embryonic stem cells under chemically defined conditions that recapitulate liver development. Hepatology, 51(5), 1754-1765.

7. Kern, S., Eichler, H., Stoeve, J., Kluter, H., \& Bieback, K. (2006). Comparative analysis of mesenchymal stem cells from bone marrow, umbilical cord blood, or adipose tissue. Stem Cells, 24(5), 1294-1301.

8. Aurich, H., Sgodda, M., Kaltwasser, P., Vetter, M., Weise, A., \& Liehr, T. (2009). Hepatocyte differentiation of mesenchymal stem cells from human adipose tissue in vitro promotes hepatic integration in vivo. Gut, 58(4), 570-581. 
9. Zhang, Y. N., Lie, P. C., \& Wei, X. (2009). Differentiation of mesenchymal stromal cells derived from umbilical cord Wharton's jelly into hepatocyte-like cells. Cytotherapy, 11(5), 548-558.

10. Newsome, P. N., Johannessen, I., Boyle, S., Dalakas, E., McAulay, K. A., Samuel, K., et al. (2003). Human cord bloodderived cells can differentiate into hepatocytes in the mouse liver with no evidence of cellular fusion. Gastroenterology, 124(7), 1891-1900.

11. Si-Tayeb, K., Lemaigre, F. P., \& Duncan, S. A. (2010). Organogenesis and development of the liver. Developmental Cell, 18(2), 175-189.

12. Lemaigre, F. P. (2009). Mechanisms of liver development: concepts for understanding liver disorders and design of novel therapies. Gastroenterology, 137(1), 62-79.

13. Gualdi, R., Bossard, P., Zheng, M., Hamada, Y., Coleman, J. R., \& Zaret, K. S. (1996). Hepatic specification of the gut endoderm in vitro: cell signaling and transcriptional control. Genes \& Development, 10(13), 1670-1682.

14. Jung, J., Zheng, M., Goldfarb, M., \& Zaret, K. S. (1999). Initiation of mammalian liver development from endoderm by fibroblast growth factors. Science, 284(5422), 1998-2003.

15. Tremblay, K. D., \& Zaret, K. S. (2005). Distinct populations of endoderm cells converge to generate the embryonic liver bud and ventral foregut tissues. Developmental Biology, 280(1), 87-99.

16. Wells, J. M., \& Melton, D. A. (2000). Early mouse endoderm is patterned by soluble factors from adjacent germ layers. Development, 127(8), 1563-1572.

17. McLin, V. A., Rankin, S. A., \& Zorn, A. M. (2007). Repression of Wnt/beta-catenin signaling in the anterior endoderm is essential for liver and pancreas development. Development, 134 (12), 2207-2217.

18. Bayha, E., Jorgensen, M. C., Serup, P., \& Grapin-Botton, A. (2009). Retinoic acid signaling organizes endodermal organ specification along the entire antero-posterior axis. PLOS ONE, 4 (6), e5845.

19. Zaret, K. S., \& Grompe, M. (2008). Generation and regeneration of cells of the liver and pancreas. Science, 322(5907), 14901494.

20. Calmont, A., Wandzioch, E., Tremblay, K. D., Minowada, G., Kaestner, K. H., Martin, G. R., et al. (2006). An FGF response pathway that mediates hepatic gene induction in embryonic endoderm cells. Developmental Cell, 11(3), 339-348.

21. Serls, A. E., Doherty, S., Parvatiyar, P., Wells, J. M., \& Deutsch, G. H. (2005). Different thresholds of fibroblast growth factors pattern the ventral foregut into liver and lung. Development, 132 (1), 35-47.

22. Huang, H., Ruan, H., Aw, M. Y., Hussain, A., Guo, L., Gao, C., et al. (2008). Mypt1-mediated spatial positioning of Bmp2producing cells is essential for liver organogenesis. Development, 135(19), 3209-3218.

23. Wandzioch, E., \& Zaret, K. S. (2009). Dynamic signaling network for the specification of embryonic pancreas and liver progenitors. Science, 324(5935), 1707-1710.

24. Huppert, S. S., \& Magnuson, M. A. (2009). New complexity in differentiating stem cells toward hepatic and pancreatic fates. Science Signaling, 2(83), 50.

25. Zaret, K. S. (2008). Genetic programming of liver and pancreas progenitors: lessons for stem-cell differentiation. Nature Reviews. Genetics, 9(5), 329-340.

26. Bort, R., Signore, M., Tremblay, K., Martinez Barbera, J. P., \& Zaret, K. S. (2006). Hex homeobox gene controls the transition of the endoderm to a pseudostratified, cell emergent epithelium for liver bud development. Developmental Biology, 290(1), 44-56.

27. Zhao, R., Watt, A. J., Li, J., Luebke-Wheeler, J., Morrisey, E. E., \& Duncan, S. A. (2005). GATA6 is essential for embryonic development of the liver but dispensable for early heart formation. Molecular and Cellular Biology, 25(7), 26222631.

28. Sosa-Pineda, B., Wigle, J. T., \& Oliver, G. (2000). Hepatocyte migration during liver development requires Prox1. Nature Genetics, 25, 254-255.

29. Ludtke, T. H., Christoffels, V. M., Petry, M., \& Kispert, A. (2009). Tbx3 promotes liver bud expansion during mouse development by suppression of cholangiocyte differentiation. Hepatology, 49(3), 969-978.

30. Margagliotti, S., Clotman, F., Pierreux, C. E., Beaudry, J. B., Jacquemin, P., Rousseau, G. G., et al. (2007). The onecut transcription factors HNF-6/OC-1 and OC-2 regulate early liver expansion by controlling hepatoblast migration. Developmental Biology, 311(2), 579-589.

31. Li, J., Ning, G., \& Duncan, S. A. (2000). Mammalian hepatocyte differentiation requires the transcription factor HNF-4alpha. Genes \& Development, 14(4), 464-474.

32. Snykers, S., De Kock, J., Rogiers, V., \& Vanhaecke, T. (2009). In vitro differentiation of embryonic and adult stem cells into hepatocytes: state of the art. Stem Cells, 27(3), 577-605.

33. Yoshimura, A., Ichihara, M., Kinjyo, I., Moriyama, M., Copeland, N. G., Gilbert, D. J., et al. (1996). Mouse oncostatin $\mathrm{M}$ : an immediate early gene induced by multiple cytokines through the JAK-STAT5 pathway. The EMBO Journal, 15(5), 1055-1063.

34. Shafritz, D. A., Oertel, M., Menthena, A., Nierhoff, D., \& Dabeva, M. D. (2006). Liver stem cells and prospects for liver reconstitution by transplanted cells. Hepatology, 43(2 Suppl 1), S89-S98.

35. Kamiya, A., Kinoshita, T., \& Miyajima, A. (2001). Oncostatin $M$ and hepatocyte growth factor induce hepatic maturation via distinct signaling pathways. FEBS Letters, 492(1-2), 90-94.

36. Cascio, S., \& Zaret, K. S. (1991). Hepatocyte differentiation initiates during endodermal-mesenchymal interactions prior to liver formation. Development, 113(1), 217-225.

37. Dabeva, M. D., \& Shafritz, D. A. (1993). Activation, proliferation, and differentiation of progenitor cells into hepatocytes in the D-galactosamine model of liver regeneration. The American Journal of Pathology, 143(6), 1606-1620.

38. Farber, E. (1956). Similarities in the sequence of early histological changes induced in the liver of the rat by ethionine, 2-acetylamino-fluorene, and 3'-methyl-4 dimethylaminoazobenzene. Cancer Research, 16(2), 142-148.

39. Evarts, R. P., Nagy, P., Nakatsukasa, H., Marsden, E., \& Thorgeirsson, S. S. (1989). In vivo differentiation of rat liver oval cells into hepatocytes. Cancer Research, 49(6), 15411547.

40. Fujio, K., Evarts, R. P., Hu, Z., Marsden, E. R., \& Thorgeirsson, S. S. (1994). Expression of stem cell factor and its receptor, c-kit, during liver regeneration from putative stem cells in adult rat. Laboratory Investigation, 70(4), 511-516.

41. Omori, N., Omori, M., Evarts, R. P., Teramoto, T., Miller, M. J., Hoang, T. N., et al. (1997). Partial cloning of rat CD34 cDNA and expression during stem cell-dependent liver regeneration in the adult rat. Hepatology, 26(3), 720-727.

42. Omori, M., Omori, N., Evarts, R. P., Teramoto, T., \& Thorgeirsson, S. S. (1997). Coexpression of flt-3 ligand/flt-3 and SCF/c-kit signal transduction system in bile-duct-ligated SI and W mice. The American Journal of Pathology, 150(4), 11791187.

43. Omori, N., Evarts, R. P., Omori, M., Hu, Z., Marsden, E. R., \& Thorgeirsson, S. S. (1996). Expression of leukemia inhibitory factor and its receptor during liver regeneration in the adult rat. Laboratory Investigation, 75(1), 15-24. 
44. Conigliaro, A., Brenner, D. A., \& Kisseleva, T. (2010). Hepatic progenitors for liver disease: current position. Stem Cells and Cloning: Advances and Applications, 3(1), 39-47.

45. Zhang, L., Theise, N., Chua, M., \& Reid, L. M. (2008). The stem cell niche of human livers: symmetry between development and regeneration. Hepatology, 48(5), 1598-1607.

46. Schmelzer, E., Zhang, L., Bruce, A., Wauthier, E., Ludlow, J., Yao, H. L., et al. (2007). Human hepatic stem cells from fetal and postnatal donors. The Journal of Experimental Medicine, 204(8), 1973-1987.

47. McClelland, R., Wauthier, E., Zhang, L., Melhem, A., Schmelzer, E., Barbier, C., et al. (2008). Ex vivo conditions for self-replication of human hepatic stem cells. Tissue Engineering Part C Methods, 14(4), 341-351.

48. Evans, M. J., \& Kaufman, M. H. (1981). Establishment in culture of pluripotential cells from mouse embryos. Nature, 292 (5819), 154-156.

49. Thomson, J. A., Itskovitz-Eldor, J., Shapiro, S. S., Waknitz, M. A., Swiergiel, J. J., Marshall, V. S., et al. (1998). Embryonic stem cell lines derived from human blastocysts. Science, 282 (5391), 1145-1147.

50. Buzzard, J. J., Gough, N. M., Crook, J. M., \& Colman, A. (2004). Karyotype of human ES cells during extended culture. Nature Biotechnology, 22(4), 381-382.

51. Heins, N., Englund, M. C., Sjoblom, C., Dahl, U., Tonning, A., Bergh, C., et al. (2004). Derivation, characterization, and differentiation of human embryonic stem cells. Stem Cells, 22 (3), 367-376

52. Reubinoff, B. E., Pera, M. F., Fong, C. Y., Trounson, A., \& Bongso, A. (2000). Embryonic stem cell lines from human blastocysts: somatic differentiation in vitro. Nature Biotechnology, 18(4), 399-404.

53. Guhr, A., Kurtz, A., Friedgen, K., \& Loser, P. (2006). Current state of human embryonic stem cell research: an overview of cell lines and their use in experimental work. Stem Cells, 24(10), 2187-2191.

54. Hwang, N. S., Varghese, S., \& Elisseeff, J. (2008). Controlled differentiation of stem cells. Advanced Drug Delivery Reviews, 60(2), 199-214

55. Abe, K., Niwa, H., Iwase, K., Takiguchi, M., Mori, M., Abe, S. I., et al. (1996). Endoderm-specific gene expression in embryonic stem cells differentiated to embryoid bodies. Experimental Cell Research, 229(1), 27-34.

56. Levinson-Dushnik, M., \& Benvenisty, N. (1997). Involvement of hepatocyte nuclear factor 3 in endoderm differentiation of embryonic stem cells. Molecular and Cellular Biology, 17(7), 3817-3822.

57. Duncan, S. A., Nagy, A., \& Chan, W. (1997). Murine gastrulation requires HNF-4 regulated gene expression in the visceral endoderm: tetraploid rescue of Hnf-4(-/-) embryos. Development, 124(2), 279-287.

58. Hamazaki, T., Iiboshi, Y., Oka, M., Papst, P. J., Meacham, A. M., Zon, L. I., et al. (2001). Hepatic maturation in differentiating embryonic stem cells in vitro. FEBS Letters, 497(1), 15-19.

59. Rambhatla, L., Chiu, C. P., Kundu, P., Peng, Y., \& Carpenter, M. K. (2003). Generation of hepatocyte-like cells from human embryonic stem cells. Cell Transplantation, 12(1), 1-11.

60. Itskovitz-Eldor, J., Schuldiner, M., Karsenti, D., Eden, A., Yanuka, O., Amit, M., et al. (2000). Differentiation of human embryonic stem cells into embryoid bodies compromising the three embryonic germ layers. Molecular Medicine, 6(2), 88-95.

61. Schuldiner, M., Yanuka, O., Itskovitz-Eldor, J., Melton, D. A., \& Benvenisty, N. (2000). Effects of eight growth factors on the differentiation of cells derived from human embryonic stem cells. Proceedings of the National Academy of Sciences of the United States of America, 97(21), 11307-11312.
62. Lavon, N., Yanuka, O., \& Benvenisty, N. (2004). Differentiation and isolation of hepatic-like cells from human embryonic stem cells. Differentiation, 72(5), 230-238.

63. Lavon, N., \& Benvenisty, N. (2005). Study of hepatocyte differentiation using embryonic stem cells. Journal of Cellular Biochemistry, 96(6), 1193-1202.

64. Shirahashi, H., Wu, J., Yamamoto, N., Catana, A., Wege, H., Wager, B., et al. (2004). Differentiation of human and mouse embryonic stem cells along a hepatocyte lineage. Cell Transplantation, 13(3), 197-211.

65. Schwartz, R. E., Linehan, J. L., Painschab, M. S., Hu, W. S., Verfaillie, C. M., \& Kaufman, D. S. (2005). Defined conditions for development of functional hepatic cells from human embryonic stem cells. Stem Cells and Development, 14(6), 643-655.

66. Baharvand, H., Hashemi, S. M., Kazemi Ashtiani, S., \& Farrokhi, A. (2006). Differentiation of human embryonic stem cells into hepatocytes in $2 \mathrm{D}$ and $3 \mathrm{D}$ culture systems in vitro. The International Journal of Developmental Biology, 50(7), 645652.

67. Baharvand, H., Hashemi, S. M., \& Shahsavani, M. (2008). Differentiation of human embryonic stem cells into functional hepatocyte-like cells in a serum-free adherent culture condition. Differentiation, 76(5), 465-477.

68. Duan, Y., Catana, A., Meng, Y., Yamamoto, N., He, S., Gupta, S., et al. (2007). Differentiation and enrichment of hepatocytelike cells from human embryonic stem cells in vitro and in vivo. Stem Cells, 25(12), 3058-3068.

69. Sulzbacher, S., Schroeder, I. S., Truong, T. T., \& Wobus, A. M. (2009). Activin A-induced differentiation of embryonic stem cells into endoderm and pancreatic progenitors-the influence of differentiation factors and culture conditions. Stem Cell Reviews, 5(2), 159-173.

70. Tam, P. P., Kanai-Azuma, M., \& Kanai, Y. (2003). Early endoderm development in vertebrates: lineage differentiation and morphogenetic function. Current Opinion in Genetics \& Development, 13(4), 393-400.

71. Chen, Y. G., Wang, Q., Lin, S. L., Chang, C. D., Chuang, J., \& Ying, S. Y. (2006). Activin signaling and its role in regulation of cell proliferation, apoptosis, and carcinogenesis. Experimental Biology and Medicine (Maywood), 231(5), 534-544.

72. Zaret, K. S. (2001). Hepatocyte differentiation: from the endoderm and beyond. Current Opinion in Genetics \& Development, 11(5), 568-574.

73. D’Amour, K. A., Agulnick, A. D., Eliazer, S., Kelly, O. G., Kroon, E., \& Baetge, E. E. (2005). Efficient differentiation of human embryonic stem cells to definitive endoderm. Nature Biotechnology, 23(12), 1534-1541.

74. Ishii, T., Fukumitsu, K., Yasuchika, K., Adachi, K., Kawase, E., Suemori, H., et al. (2008). Effects of extracellular matrixes and growth factors on the hepatic differentiation of human embryonic stem cells. American Journal of Physiology. Gastrointestinal and Liver Physiology, 295(2), G313-G321.

75. Brolen, G., Sivertsson, L., Bjorquist, P., Eriksson, G., Ek, M., Semb, H., et al. (2010). Hepatocyte-like cells derived from human embryonic stem cells specifically via definitive endoderm and a progenitor stage. Journal of Biotechnology, 145(3), 284-294.

76. Hay, D. C., Fletcher, J., Payne, C., Terrace, J. D., Gallagher, R. C., Snoeys, J., et al. (2008). Highly efficient differentiation of hESCs to functional hepatic endoderm requires ActivinA and Wnt3a signaling. Proceedings of the National Academy of Sciences of the United States of America, 105(34), 1230112306.

77. Cai, J., Zhao, Y., Liu, Y., Ye, F., Song, Z., Qin, H., et al. (2007). Directed differentiation of human embryonic stem cells into functional hepatic cells. Hepatology, 45(5), 1229-1239. 
78. Hay, D. C., Zhao, D., Ross, A., Mandalam, R., Lebkowski, J., \& Cui, W. (2007). Direct differentiation of human embryonic stem cells to hepatocyte-like cells exhibiting functional activities. Cloning and Stem Cells, 9(1), 51-62.

79. Johannesson, M., Stahlberg, A., Ameri, J., Sand, F. W., Norrman, K., \& Semb, H. (2009). FGF4 and retinoic acid direct differentiation of hESCs into PDX1-expressing foregut endoderm in a time- and concentration-dependent manner. PLoS ONE, 4(3), e4794.

80. Ameri, J., Stahlberg, A., Pedersen, J., Johansson, J. K., Johannesson, M. M., Artner, I., et al. (2010). FGF2 specifies hESC-derived definitive endoderm into foregut/midgut cell lineages in a concentration-dependent manner. Stem Cells, 28 (1), 45-56.

81. Agarwal, S., Holton, K. L., \& Lanza, R. (2008). Efficient differentiation of functional hepatocytes from human embryonic stem cells. Stem Cells, 26(5), 1117-1127.

82. Pei, H., Yang, Y., Xi, J., Bai, Z., Yue, W., Nan, X., et al. (2009). Lineage restriction and differentiation of human embryonic stem cells into hepatic progenitors and zone 1 hepatocytes. Tissue Engineering Part C Methods, 15(1), 95-104.

83. Zhao, D., Chen, S., Cai, J., Guo, Y., Song, Z., Che, J., et al. (2009). Derivation and characterization of hepatic progenitor cells from human embryonic stem cells. PLoS ONE, 4(7), e6468.

84. Takahashi, K., \& Yamanaka, S. (2006). Induction of pluripotent stem cells from mouse embryonic and adult fibroblast cultures by defined factors. Cell, 126(4), 663-676.

85. Okita, K., \& Yamanaka, S. (2010). Induction of pluripotency by defined factors. Experimental Cell Research, 316(16), 2565-2570.

86. Yamanaka, S., \& Blau, H. M. (2010). Nuclear reprogramming to a pluripotent state by three approaches. Nature, 465(7299), 704712.

87. Yamanaka, S. (2009). A fresh look at iPS cells. Cell, 137(1), 13-17.

88. Liu, H., Ye, Z., Kim, Y., Sharkis, S., \& Jang, Y. Y. (2010). Generation of endoderm-derived human induced pluripotent stem cells from primary hepatocytes. Hepatology, 51(5), 1810 1819.

89. Gunaseeli, I., Doss, M. X., Antzelevitch, C., Hescheler, J., \& Sachinidis, A. (2010). Induced pluripotent stem cells as a model for accelerated patient- and disease-specific drug discovery. Current Medicinal Chemistry, 17(8), 759-766.

90. Grigoriadis, A. E., Kennedy, M., Bozec, A., Brunton, F., Stenbeck, G., Park, I. H., et al. (2010). Directed differentiation of hematopoietic precursors and functional osteoclasts from human ES and iPS cells. Blood, 115(14), 2769-2776.

91. Zhang, D., Jiang, W., Liu, M., Sui, X., Yin, X., Chen, S., et al. (2009). Highly efficient differentiation of human ES cells and iPS cells into mature pancreatic insulin-producing cells. Cell Research, 19(4), 429-438.

92. Gai, H., Leung, E. L., Costantino, P. D., Aguila, J. R., Nguyen, D. M., Fink, L. M., et al. (2009). Generation and characterization of functional cardiomyocytes using induced pluripotent stem cells derived from human fibroblasts. Cell Biology International, 33(11), 1184-1193.

93. Viczian, A. S., Solessio, E. C., Lyou, Y., \& Zuber, M. E. (2009). Generation of functional eyes from pluripotent cells. PLoS Biology, 7(8), e1000174.

94. Chambers, S. M., Fasano, C. A., Papapetrou, E. P., Tomishima, M., Sadelain, M., \& Studer, L. (2009). Highly efficient neural conversion of human ES and iPS cells by dual inhibition of SMAD signaling. Nature Biotechnology, 27(3), 275-280.
95. Boland, M. J., Hazen, J. L., Nazor, K. L., Rodriguez, A. R., Gifford, W., Martin, G., et al. (2009). Adult mice generated from induced pluripotent stem cells. Nature, 461(7260), 91-94.

96. Zhao, X. Y., Li, W., Lv, Z., Liu, L., Tong, M., Hai, T., et al. (2010). Viable fertile mice generated from fully pluripotent iPS cells derived from adult somatic cells. Stem Cell Reviews, 6(3), 390-397.

97. Gai, H., Nguyen, D. M., Moon, Y. J., Aguila, J. R., Fink, L. M., Ward, D. C., et al. (2010). Generation of murine hepatic lineage cells from induced pluripotent stem cells. Differentiation, 79(3), 171-181.

98. Li, W., Wang, D., Qin, J., Liu, C., Zhang, Q., Zhang, X., et al. (2010). Generation of functional hepatocytes from mouse induced pluripotent stem cells. Journal of Cellular Physiology, 222(3), 492-501.

99. Si-Tayeb, K., Noto, F. K., Nagaoka, M., Li, J., Battle, M. A., Duris, C., et al. (2010). Highly efficient generation of human hepatocyte-like cells from induced pluripotent stem cells. Hepatology, 51(1), 297-305.

100. Song, Z., Cai, J., Liu, Y., Zhao, D., Yong, J., Duo, S., et al. (2009). Efficient generation of hepatocyte-like cells from human induced pluripotent stem cells. Cell Research, 19(11), 12331242.

101. Sullivan, G. J., Hay, D. C., Park, I. H., Fletcher, J., Hannoun, Z., Payne, C. M., et al. (2010). Generation of functional human hepatic endoderm from human induced pluripotent stem cells. Hepatology, 51(1), 329-335.

102. Simon, M. C., \& Keith, B. (2008). The role of oxygen availability in embryonic development and stem cell function. Nature Reviews. Molecular Cell Biology, 9(4), 285-296.

103. Wion, D., Christen, T., Barbier, E. L., \& Coles, J. A. (2009). PO (2) matters in stem cell culture. Cell Stem Cell, 5(3), 242-243.

104. Millman, J. R., Tan, J. H., \& Colton, C. K. (2009). The effects of low oxygen on self-renewal and differentiation of embryonic stem cells. Current Opinion in Organ Transplantation, 14(6), 694-700.

105. Hannoun, Z., Filippi, C., Sullivan, G., Hay, D. C., \& Iredale, J. P. (2010). Hepatic endoderm differentiation from human embryonic stem cells. Current Stem Cell Research \& Therapy, 5(3), 233244.

106. Cooke, A. R., Harrison, D. D., \& Skyring, A. P. (1963). Use of indocyanine green as a test of liver function. The American Journal of Digestive Diseases, 8, 244-250.

107. Ek, M., Soderdahl, T., Kuppers-Munther, B., Edsbagge, J., Andersson, T. B., Bjorquist, P., et al. (2007). Expression of drug metabolizing enzymes in hepatocyte-like cells derived from human embryonic stem cells. Biochemical Pharmacology, 74 (3), 496-503.

108. Manohar, R., \& Lagasse, E. (2009). Transdetermination: a new trend in cellular reprogramming. Molecular Therapy, 17(6), 936-938.

109. Vierbuchen, T., Ostermeier, A., Pang, Z. P., Kokubu, Y., Sudhof, T. C., \& Wernig, M. (2010). Direct conversion of fibroblasts to functional neurons by defined factors. Nature, 463(7284), 10351041.

110. Ieda, M., Fu, J. D., Delgado-Olguin, P., Vedantham, V., Hayashi, Y., Bruneau, B. G., et al. (2010). Direct reprogramming of fibroblasts into functional cardiomyocytes by defined factors. Cell, 142(3), 375-386.

111. Nicholas, C. R., \& Kriegstein, A. R. (2010). Regenerative medicine: cell reprogramming gets direct. Nature, 463(7284), $1031-1032$ 